\title{
LA CELIA DE LOPE DE VEGA ¿UN MISTERIO RESUELTO?
}

Entre las muchas mujeres que pueblan la vida amorosa de Lope de Vega, quizá ninguna plantee más problemas que una denominada poéticamente Celia. Numerosas referencias a esta amada del dramaturgo fueron recogidas en un extenso estudio por María Goyri de Menéndez Pidal, publicado en esta revista ${ }^{1}$. A juzgar por sus alusiones literarias, Lope tuvo amores con Celia aproximadamente desde 1594 hasta $1601^{2}$. María Goyri propuso identificar a la misteriosa Celia con Micaela de Luján, cantada por Lope bajo el nombre de Lucinda, basándose principalmente en la semejanza de sus respectivas descripciones poéticas. Esta teoría implicaba varios cambios importantes en lo que se sabía de la vida del poeta: en primer lugar, tal identificación modificaba las fechas de los amores de Lope con Micaela, que sólo se habían documentado de 1599 a 1608, y en segundo, parasus otros argumentos doña María proponía cambiar de 1596 a 1593 la fecha de la comedia Los comendadores de Córdoba. S. Griswold Morley y Courtney Bruer$\operatorname{ton}^{3}$ rebatieron los argumentos de María Goyri, señalando que la identificación de Celia con Lucinda se basaba casi enteramente en el parecido de ciertos rasgos físicos genéricos, como "boca risueña" y "nevado pecho". Agregaron estos investigadores que una alusión hecha en 1593 a una comedia titulada Los comendadores debía referirse a una obra distinta de la de Lope, ya que la métrica de Lope no admite esta última fecha ${ }^{4}$. En lugar de identificar a Celia con Lucinda, los doctos norteamericanos propusieron: "Quizá el nombre de Celia. . . le

1 "La Celia de Lope de Vega", NRFH, 4 (1950), 347-390; luego reproducido con pequeñas adiciones en De Lope de Vega y del Romancero, Zaragoza, 1953, pp. 103-174 (citamos por esta última versión).

2 Resulta difícil precisar la fecha exacta en que Lope comenzó a nombrar a Celia en sus obras, ya que las primeras alusiones, al pareecr, son de poesías sin fecha (Goyri, pp. 124-1 26, examina unos romances sólo fechables de 1590 a 1600). La primera referencia con fecha segura parece ser la de la comedia San Segundo de Avila, firmada por Lope en Alba de Tormes el 12 de agosto de 1594. Como veremos más adelante, las alusiones se vuelven negativas 0 desaparecen hacia finales de 1601, scñalando que el amorío ya había terminado.

3 'Lope, Celia y Los comendadores de Córdoba', NRFH, 6 (1952), 57-68.

4 Los argumentos de María Goyri refutados por Morley y Bruerton son variados y complejos, pero creo que los aquí resumidos son los más decisivos. Doña María también aduce como prueba un paralclo entre unos romances alusivos a Celia y un episodio referente a Micacla en La Jerusalén conquistada: en ambos casos un tercero termina por conquistar para sí a una mujer que ha debido solicitar para otro (Goyri, pp. 125-126 y 163-164). Sin cmbargo, la autora misma reconoce que se trata de "un tema repetido mil veces en la literatura y en la historia" (p. 126). Asimismo supone doña María que "es corriente que los poetas llamen a sus amadas de varias mancras" (pp. 159-160). Es cierto que en su edad madura Lope llamó Amarilis y Marcia Leonarda (o sólo Leonarda) a Marta de Nevares, pero en sus amores anteriores había utilizado un solo nombre poético para cada mujer: Filis (Elena Osorio), Belisa (Isabel de Urbina), Lucinda o Camila Lucinda (Micacla de Luján), Gerarda (Jerónima de Burgos). 
servía [a Lope] para agrupar poéticamente varias crisis emotivas que había experimentado con más de una mujer" (p.61).

Otro distinguido lopista también discrepó con las conclusiones de María Goyri respecto a Celia y Lucinda: en 1958 Joaquín de Entrambasaguas ${ }^{5}$ criticó severamente el trabajo de doña María, aportando una noticia fundamental para confutarlo: en 1918 Juan Millé y Giménez ${ }^{6}$ había destacado un pasaje del Quijote de Avellaneda donde dice el protagonista: "Y le escribo... más heroicas poesías que. .. ha hecho Lope de Vega a su Filis, Celia, Lucinda, ni a las demás que tan divinamente ha celebrado. ."7 Tanto para Entrambasaguas como para Millé, este pasaje aclaraba toda duda respecto a Celia y Lucinda: "los contemporáneos de Lope las tenían por personas distintas. . "8 Entrambasaguas también acepta la identificación propuesta por Millé para tan misteriosa mujer: la alegre viuda Antonia de Trillo de Armenta, procesada por amancebamiento con Lope en 1596. Debe notarse que esta última fecha cae de lleno en el período de las alusiones a Celia y por tanto su candidatura no presupone las dislocaciones de cronología lopesca que acarrea la identificación con Micaela de Luján.

En la veintena de años que ha trascurrido desde el estudio de Entrambasaguas, la crítica se ha mostrado reacia a aceptar sus conclusiones (que son las mismas de Millé): tanto que Celia no debe confundirse con Lucinda, como que el nombre puede aludir a la Trillo. Por ejemplo, Fernando Lázaro Carreter, en su libro sobre el Fénix", afirma que Lope Ilama a Micaela "primero Celia, y después Camila Lucinda. . ." (p. 39). Sin embargo, pocos años más tarde el ilustre crítico por lo visto aceptaba la idea de Millé y Entrambasaguas de que "... Celia y Lucinda parecen ser mujeres distintas. .."10 Francisco Rico, en cambio, todavía admitía en 1968 la posibilidad de que la Luján fuera Celia ${ }^{1}{ }^{1}$. Es de observar que ni Lázaro Carreter ni Rico mencionan la identificación de Celia con la Trillo. La mayoría de los últimos investigadores -Fernando García Salinero, Martín de Riquer, Alfonso Zamora Vicente, Edwin S. Morby-o pasan la cuestión por alto $^{12}$ o prudentemente se abstienen de tomar partido en este asunto francamente espinoso ${ }^{13}$. Sólo Rafael Osuna, refiriéndose a las teorías de María Goyri, y de Morley y Bruerton, concluye que "ninguna de las identificaciones es por el momento definitivamente aceptable"14. Y luego agrega la aguda observación (hecha a propósito de un soneto a Celia en $L a$ Arcadia $^{15}$ ) de que "Lope revela

5 Estudios sobre Lope de Vega, Madrid, 1958, t. 3, pp. 269-271.

6 "Un soneto interesante para las biografías de Lope y de Quevedo", Helios, 1 (1918), 92-110; esp. pp. 104-107.

7 Alonso Fernández de AVEllaneda, Don Quijote de la Mancha, ed. Martín de Riquer, Madrid, 1972, t. 1, pp. 45-46.

8 Millé, p. 106, nota 34, cit. por Entrambasaguas, p. 269, nota 42.

9 Lope de Vega, Introducción a su vida y su obra, Salamanca, 1966.

10 En sus muy útiles "Adiciones" a la Vida de Lope de Vega (1562-1635) de Hugo A. Rennert y Américo Castro, Salamanca, 1969, p. 528.

11 En su edición de El caballero de Olmedo, Salamanca, 1968, p. 9.

12 Ni García Salinero ni Riquer anotan el pasaje antes citado del Quijote apócrifo en sus respectivas ediciones (la de Riquer queda citada en nuestra nota 7; la de García Salinero se publicó en Madrid en 1971). Zamora Vicente omite toda alusión a Celia en su Lope de Vega, Madrid, 1961.

13 Morby, en su edición de La Arcadia, Madrid, 1975, p. 12, alude a los argumentos de Goyri y los de Morley y Bruerton, pero sin optar por ninguna de las dos alternativas.

14 "La Arcadia" de Lope de Vega: génesis, estructura y originalidad, Madrid, 1972, p. 138.

15 Es el que comienza "si la grana del labio Celia mueve..." (P. 263 en la edición de Morby). 
un cuidado extremo en vclar toda huella ..." Esta atención al secreto en torno a Celia constituye un punto fundamental sobre el que hemos de volver en breve; por ahora notemos de paso que esta misma reserva sin duda ha creado el misterio que hoy en día rodea a esta mujer amada por Lope.

La dificultad en identificar a Celia queda realzada por la eminencia de los lopistas que han expresado pareceres contrarios o que han juzgado más acertado no tomar cartas en ella. A pesar de lo arriesgado de formular teorías en una materia tan escurridiza, el deseo de hacer una pequeña aportación a la biografía del Fénix me anima a exponer mi opinión, y a dar a conocer un dato nuevo que ayudará a esclarecer tan sugestivo incógnito.

En cuanto a las identificaciones de Celia con la Luján o con varias mujeres amadas por el poeta, me parece que tanto la teoría de María Goyri como la de Morley y Bruerton caen por su propio peso: por un lado, no es nada convincente suponer que dos mujeres sean la misma solamente porque el poeta les atribuya ciertos rasgos comunes; tales semejanzas existen entre todas las amadas descritas poéticamente (mucho tienen en común las descripciones de Beatrice, Laura, doña Endrina, Melibea e Isabel Freire, para mencionar unos pocos ejemplos); cuando a esto se agrega la necesidad de modificar las fechas de obras (como Los comendadores de Córdoba) que se han fechado ya con métodos objetivos, se hace evidente que hay que buscar una explicación que reconcilie mejor los diversos hechos conocidos. Por otra parte, todo lo que sabemos de los nombres poéticos inventados por Lope nos enseña que él daba tales apelativos a mujeres concretas que amaba; nada hay que indique que agrupara a varias mujeres bajo un solo nombre; tampoco es éste un procedimiento común, para que dijéramos que Lope sólo se asemeja a otros en este respecto. Por si quedara alguna duda, creo que el pasaje de Avellaneda impone definitivamente la conclusión de que Celia era una mujer distinta de las otras queridas por Lope.

Para identificar a la enigmática desconocida, conviene registrar la biografía del Fénix para averiguar cuáles fueron las damas amadas por él durante los años en que celebraba a Celia (esto es, más o menos de 1594 a 1601), y eligir la que mejor concuerde con los datos disponibles. De las diferentes mujeres cantadas por Lope durante este período, Elena Osorio e Isabel de Urbina tienen otros nombres poéticos (Filis, Belisa) y también sus historias bien desarrolladas. Hacia el final del mismo lapso (a partir de 1599) aparece Micaela de Luján, igualmente con su nombre e historia propios. La única amante que queda, entonces, es doña Antonia de Trillo de Armenta, la cual sería pariente cercana (¿hermana?) de la Marcela Trillo de Armenta que estuvo con Lope en Alba de Tormes, al servicio del duque de Alba, hacia 1592-1595 ${ }^{16}$.

Bastantes documentos se conservan acerca de Antonia de Trillo: sabemos

16 Véase CAYETANO DE LA BARRERA Y LEIRADO, Nueva biografía, cn Obras de Lope de Vega, Madrid, 1890, t. 1, pp. $57-58$ (citado por Morley y Bruerton, p. 65). Tanto de la Barrera como Morley y Bruerton creen que Marcela y Antonia Trillo pueden ser la misma, o paricntas cercanas (opinión también compartida por Morby, cd. La Arcadia, p. 58 , nota 7). La Barrera cree que el nombre Antonia del proceso por amancebamiento "la podido ser transcrito equivocadamente" (p. 58), pero asi figura en muchos documentos (véanse A. TOMIllo y C. PÉrez PAStor, Proceso de Lope de Vega por libelos contra unos cómicos, Madrid, 1901, pp. 228-232, y FRANCISCO R. DE UHAGÓN, cd., Dos novelas de Salas Barbadillo, Madrid, 1894, pp. xxiv-xxix, citados por RENNER t y CASTRo, Vida de Lope, p: 100, nota 55), y en la dedicatoria de un soneto autógrafo de Lope que luego mencionaremos. Además, se conserva su tirma, que claramente reza Antonia (reproducida por LUis ASTRANA MARÍn, Vida azarosa de Lope de Vega, Barcelona, 1935, p. 161). 
que era de buena familia (su padre, Alonso de Trillo, era alférez, y su madre, María de Laredo, gastaba un doña por delante), que en 1582 se casó bien (con un don Luis Puche, barcelonés, muerto antes de 1595), que celebró segundas nupcias en 1601 (con un tal Pablo Moreno, fallecido en 1623), y que en septiembre de 1609 el novelista Salas Barbadillo compuso unos versos satíricos en contra de ella y de otras mujeres y sus maridos, porque admitían galanes ${ }^{17}$. Además, su parienta Marcela Trillo escribió unos versos laudatorios para La Arcadia de Lope (1598) y otros para su Isidro, publicado en 1599. Un interés especial reviste el hecho de que en las ediciones subsiguientes del Isidro, a partir de 1602, se omite el nombre de Marcela de estos versos ${ }^{18}$ (los cuales en todo caso serían fruto de la imaginación de Lope ${ }^{19}$ ). Paralelamente, en la edición valenciana de 1602 de La Arcadia, se inserta un soneto de don Carlos Boyl -buen amigo de Lope-que en éste alude al "rigor que usó [Celia] contigo", y se refiere a su "engaño" 20

Igualmente interesante para nuestro propósito es que en Los comendadores de Córdoba figura un elogio de la familia Trillo, encomio que "difícilmente habría podido ser introducido sino como homenaje a Antonia" 1 . Esta comedia data de 1596, el mismo año del proceso de doña Antonia y Lope por concubinato. Hay más: este drama contiene un soneto ("Ya no quiero más bien que sólo amaros. ..") que también existe en un autógrafo que lleva el epígrafe "Para doña Antonia Trillo, señora" 2 . Significativamente, la versión de Los comendadores (Ac. XI, p. 272c) se dirige a una "señora" anónima donde el soneto dice "Antonia" "23. Por último, se introduce en Los comendadores, al comienzo del acto III, una doncella llamada Antonia para que cante una canción premonitoria. Parece evidente que tan discreta introducción del nombre de la amada complementa la alusión anterior a su apellido. He aquí, pues, una mujer cuyas relaciones con Lope, probablemente iniciadas cuando éste estaba en Alba de Tormes $^{24}$ y continuadas hasta 1601 , coinciden exactamente con la época de las menciones de Celia, de 1594 a 1601 . Conjuntamente, estas relaciones revelan el mismo sigilo característico de Celia. Parece claro, por lo tanto, que debemos considerar muy seriamente la idea de Millé y Entrambasaguas de que la Trillo procesada por amancebamiento con Lope sea la mejor candidata para el nombre poérico de Celia.

Antes de proseguir, resumamos lo ya sabido acerca de Celia, apurando más los datos para obtener todas las conclusiones razonables que contengan: sabemos

17 Véanse TOMILlo y PÉrez PASTOR, Proceso, y Uhagón, Dos novelas, en las páginas ya citadas en la nota anterior.

18 LA BARRERA, p. 57.

19 La Arcadia, cd. Morby, p. 58, nota 7.

20 La Arcadia, cd. Morby, pp. 458-459.

21 MORLEY y BRUERTON, p. 63.

22 Se hallarán detalles y bibliografías en Obras poéticas de Lope, ed. J. M. Blecua, Barcelona, 1969, t. 1, p. 102.

23 Más tarde Lope cambió "Antonia" por "Lucinda" y dedicó cl soneto a Micacla de Luján; véanse BLECUA, p. 102 y GOYRI, pp. 134-136.

24 Millé scñala (pp. 104-105) que el áfán de Lope por volver a Madrid en 1595, después de la muerte de Isabel de Urbina en Alba de Tormes, obedecería al acicate de Celia, clue vivía en la corte. Agreguemos que consta documentalmente que en 1595 Antonia de Trillo residía en Madrid. donde vivía desde hacía años, y que ya era viuda (Tomillo y Pérez Pastor, Proceso, pp. 228-229). 
que Celia fue una de las mujeres amadas por Lope, pues éste la aludió en numerosas obras (poesías, comedias, la novela La Arcadia) durante los años 1594 a 1601. Sin embargo, no todas las Celias de sus obras constituyen referencias a este amor -hay personajes que llevan este nombre en 63 comedias auténticas del Fénix, y dichos personajes representan las más diversas condiciones sociales (reinas, nobles, damas, dueñas, criadas, actrices, villanas, labradoras) y nacionalidades (españolas, portuguesas, italianas, francesas, alemanas, griegas, húngaras" ${ }^{25}$. Además -y éste es un hecho de mucha importancia que no se ha destacado hasta ahora - no hay ninguna historia peculiar que se asocie con estas Celias. A diferencia de Elena Osorio, Isabel de Urbina, Juana de Guardo, Micaela de Luján, Jerónima de Burgos, Lucía Salcedo y Marta de Nevares, Celia no aparece en las obras de Lope con cualidades ni acciones propias que la distingan. Es simplemente una bella mujer amada por el poeta. Se ve que Lope ha procedido con extremada prudencia en este caso, guardándose de sacar a la luz pública detalles personales que pudieran ofender la sensibilidad de Celia.

¿A qué factores puede obedecer este recato? Sin duda, al menos en parte, a la modestia individual (verdadera o fingida - probablemente la última, dados los pasos en que ella andaba) de la mujer; pero habrán mediado otras consideraciones también. Lo que llama la atención acerca de las otras amantes de Lope es que son plebeyas (todas eran del pueblo, y todas eran actrices; una de sus esposas -la Guardo-- también era de origen humilde. Únicamente doña Isabel de Urbina era de distinguida familia). Si las otras amantes eran plebeyas y actrices, y si Lope contaba libremente sus historias amorosas en sus obras, por contraposición no parece atrevido conjeturar que Celia bien podría ser de condición social más elevada, y por consiguiente no sería actriz. Siendo Celia de estimable alcurnia, tendría su papel en el escenario de la sociedad, y no le haría gracia salir sin máscara a las tablas de los teatros ni en la poesía - ese exhibicionismo lo dejaba para las de más bajo estracto social.

Examinemos este retrato parcialmente objetivo y parcialmente hipotético de Celia, para ver si casa bien con lo que sabemos de doña Antonia de Trillo. Desde luego, ésta es la única mujer entre todas las amantes conocidas de Lope que llena el requisito de ser de buena clase social. Cuando juntamos esta circunstancia con el hecho de que sea doña Antonia precisamente la única que cuadra dentro de la cronología de las menciones de Celia, ya parece bastante segura la identificación (sobre todo en vista de que las otras candidatas no reúnen ninguna de estas condiciones). Otra coincidencia bien curiosa: Celia rehuía la notoriedad en sus amores con Lope, y lo mismo hacía Antonia de Trillo, puesto que sólo sabemos de sus relaciones con él por el proceso de 1596 (por consiguiente, la denuncia del concubinato parece haber tenido justamente la intención de hacer público lo que Antonia y Lope procuraban mantener en secreto) ${ }^{26}$.

Pues bien, hace poco descubrimos otro dato que viene a arrojar más luz sobre el misterio de Celia. En el manuscrito de La bella malmaridada, copiado del aho-

25 Tomamos estos datos de S. G. MORLEY y RICHARD W. TYLER, Los nombres de personajes en las comedias de Lope de Vega, Berkeley y Los Angeles, 1961, pp. 213-214.

26 Algunos biógrafos creen que Antonia y Lope saldrían libres del juicio, ya que la pena para el concubinato era destierro, y se sabe que el poeta pasó por lo menos buena parte del año 1596 en Madrid (véanse ASTR ANA MARÍN, Vida azorosa, p。162, y AGUSTÍN G. DE AMEZÚA Y MAYO, Opúsculos histórico-literarios, Madrid, 1953, t. 2, p. 411). Sin embargo, Millé -basándose en el soneto "Vos de Pisuerga nuevamente Anfriso..."-cree posible que Lope saliera desterrado de Cádiz, donde estaría presente en el asalto de los ingleses en la primera mitad de julio de 1596. 
ra perdido autógrafo por Ignacio de Gálvez en $1762^{27}$, se constata un hecho bien peregrino: el censor Tomás Gracián Dantisco - muy contra su costumbre ${ }^{\mathbf{2 8}}$ estipula en su censura que han de introducirse varios cambios en el texto antes de su representación. La enmienda que aquí nos interesa consiste en que una alusión de Belardo a su amada Celia debe cambiarse a Fabia ${ }^{29}$. Sucede que Gracián Dantisco era buen amigo de Lope ${ }^{30}$, y por lo tanto estaba al corriente de sus amoríos. Pero lo llamativo es que el censor ordene cambiar esta alusión, siendo que Lope tenía por costumbre referirse a sus amadas - o ex-amadas- en sus comedias, inclusive echándoles en ocasiones pullas e insultos, sin que interviniera para nada el censor ${ }^{31}$. ¿En qué difiere esta referencia a Celia de muchas que aparecen en docenas de obras del Fénix, para que Gracián Dantisco la censure? La alusión nada tiene de ofensivo, de manera que es preciso buscar la causa en otras circunstancias. Creo que la explicación se halla en el hecho de que Lope terminó La bella malmaridada el 17 de diciembre de 1596 -año en que estaba en la plena furia de sus amores con la Trillo, a juzgar por el proceso. Pero la censura de Gracián Dantisco es posterior en cinco años (30 de octubre de 1601). ¿Qué sucedería durante este lustro que Celia ya no quisiera oírse nombrada en las tablas de los teatros púbilicos? Si identificamos a Celia con Micaela de Luján o con otras mujeres, la pregunta no tiene respuesta satisfactoria (por ejemplo, Micaela era el nuevo amor de Lope, y sus relaciones habían de continuar durante otros siete años). Pero si Celia era doña Antonia de Trillo, como venimos afirmando, existía un motivo muy fácil de comprender: doña Antonia se había casado en $1601^{32}$, y por lo tanto era más natural que ni ella ni su marido quisieran oír referencias públicas a su pasado. Aquí tenemos también la explicación por qué de 1602 en adelante Lope quitó el nombre de Marcela Trillo de los versos laudatorios del Isidro: cuando Antonia volvió a casarse, ella y su confidente en amores necesariamente tendrían que romper con el antiguo amante. Por lo visto, la rotura no fue del todo amigable. Gracián Dantisco ahorró pesadumbres a Antonia y a Lope al borrar la alusión a un amorío que ambos querrían olvidar.

DONALD MCGRADY

University of Virginia.

27 Véase A. G. DE AMEZÚ A, Una colección manuscrita y desconocida de comedias de Lope de Vega Carpio, Madrid, 1945, especialmente p. 30.

28 De doce comcdias de Lope examinadas por Gracián Dantisco entre 1590 y 1617 (El principe inocente, 1590; El leal criado, 1594; El cuerdo loco, 1602; El príncipe despeñado, 1602; El cordobés valeroso, 1603; La prueba de los amigos, 1604; La batalla del honor, 1608; La dama boba, 1613; El galán de la Membrilla, 1615; El sembrar en buena tierra, 1616; El desdén vengado, 1617), sólo El leal criado tiene cnmiendas (se cambian los lugares de acción de Francia a un país imaginario, por respeto de la paz hecha con los franceses después de escrita la comedia; cf. AcadN. t. 7, p. 190).

29 El contex to de la enmienda es el siguiente: "¿Hay nuevo gusto [ = amor de Lope]? -Extremado. / Si es Celia, tiene razón" (vs. 2864-2865, AcadN , t. 3, p.639c). Preparamos, en colaboración con Suzanne Freeman Terry, una cdición de esta comedia. De este texto dicc Amezúa que "puede considerarse como nuevo y distinto del publicado en las ediciones académicas" (Una colección, pp. 79-80).

30 El sembrar en buena tierra, ed. William L. Fichter, Nucva York y Londres, 1944, p. 236.

31 Para unas referencias denigratorias a Jerónima de Burgos, véase D. MCGR ADY, "Notes on Jerónima de Burgos in the life and work of Lope de Vega", HR, 40 (1972), 428-441.

32 Estaba ya casada el 2 de mayo; véase Tomillo y Pérez PAStor, Proceso, p. 22. 